\title{
Feminização do curso de odontologia da Universidade Estadual de Montes Claros
}

\author{
Feminization of the odontology course \\ at the State University of M ontes Claros, M inas Gerais State
}

Simone de M elo Costa ${ }^{1}$

Sarah J aneAlves Durães ${ }^{2}$

M auro Henrique N ogueira Guimarães deA breu ${ }^{3}$

${ }^{1}$ Departamento de Odontologia, Universidade Estadual de M ontes Claros. Av. Dr Ruy Braga, Campus Universitário Professor Darcy Ribeiro, Prédio 6, Vila M auricéia. 39401-089 M ontes Claros M G. smelocosta@gmail.com ${ }^{2}$ Departamento de Educação, Universidade Estadual de M ontes Claros. ${ }^{3}$ Departamento de Odontologia Social e Preventiva, Faculdade de Odontologia, Universidade Federal de M inas Gerais.
Abstract This articlesubstantiates the feminization of the odontology course starting from the case study of the $U$ niversidade Estadual de $M$ ontes Claros - Unimontes, Brazil, and its relation with some explanations that can be found at specialized literature. Its subject of analysis is the empirical data about the number of people, by gender, enrolled in the entrance examination and that has concluded the course at the university during the period of 1997 and 2006. Since its establishment, the odontology course of U nimontes has been having a higher percentage of women since the number entrance examination or entering, and also that has been concluded it. The analyzed literature source is according to the empirical data from the present case study. It was concluded that the feminization phenomena also occurs in the odontology course of U nimontes. Key words Dentistry, Dental education, Women working, Gender relations, O dontology
Resumo Esteartigo fundamenta a tese de "feminização" da odontologia através da literatura especializada no tema e concentra na revisão bibliográfica a análise deste fenômeno. Para ilustrar, re alizou-se um estudo de caso analisando o número de inscritos no processo seletivo para odontologia na U niversidade Estadual de M ontes Claros Unimontes, Brasil, apresentando os selecionadose concluintes, por sexo. A análise refere se aos anos de 1997 a 2006. 0 curso desde sua implantação tem apresentado maior porcentagem de mulheres, tanto com relação aos ingressantes e concluintes, como no processo seletivo. 0 referencial teórico analisado vai ao encontro dos dadosempíricos desseestudo de caso, donde se conclui que o fenômeno da feminização também ocorre no curso de odontologia da Unimontes.

Palavras-chave 0 dontologia, Educação em odontologia, Trabalho feminino, Relações degênero 
Introdução

A odontologia, historicamente, tem sido caracterizada como uma profissão tipicamente masculina. No entanto, atual mente, tem-sediscutido que ela passa por um processo crescente de feminização. Esse termo é também utilizado na literatura como feminilização e se refere, normalmente, a um franco crescimento da população feminina em algumas profissões que historicamente eram desempenhadas pelos homens, como exemplo medicina e odontologia. Entretanto, neste artigo o termo feminização deve ser entendido não somente como um processo de alteração quantitativa demulheresem determinada área ou setor de trabal ho, por exemplo, mas como uma alteração qual itativa de atributos masculinos ou femininos que tendem a ser associados às atividades desenvolvidas dentro das ocupações.

No Brasil, e não somente na área de odontologia, os dados revelam que as mulheres constituem a maior parte dos estudantes de nível superior do país. Em vários cursos universitários, as mulheres já ocupam metade das vagas oferecidas. Para Guedes¹, a entrada das mulheres nas universidades brasileiras é um marco das mudanças em andamento na nossa sociedade, quando se trata das relações de gênero. A autora também menciona que, na década de setenta, a entrada das mulheres nas instituições de ensino quebra a tradição da universidade como espaço masculino. Pode-se afirmar que o índice de escolaridade das mulheres aumentou quando comparado o censo de 1970 com o de 2000, sendo o aumento na educação superior o mais expressivo. Em 1970, 25\% da população com nível universitário eram compostas por mulheres. Essa proporção salta para 53\% em 2000.

Conforme Schwartzman ${ }^{2}$, o aumento do número de mulheres no ensino superior caracteriza o processo de expansão do último degrau da pirâmide da educação em todo o mundo. Para Bruschini ${ }^{3}$, esse aumento, no Brasil, também é fruto do processo de modernização e de mudança cultural no nosso país, sendo cada vez mais intensa a associação entre a escolaridade e a participação das mulheres no mercado de trabal ho.

As transformações nos padrões culturais e nos valores do papel social da mulher, intensificadas pelas consequências dos movimentos feministas a partir dos anos setenta e pela presença progressivamente atuante das mulheres nos espaços públicos, alteraram a identidadefeminina. Assim, as mulheres voltam-se, cada vez mais, para o trabalho produtivo ${ }^{3}$.
$\mathrm{Na}$ sociedade brasileira, tem ocorrido um aumento da inserção das mulheres em profissões tradicionalmente masculinas e que usufruem de elevado prestígio, como éo caso da medicina4.

A consolidação dessas mudanças mencionadas anteriormente é uma das justificativas deste estudo de caso, realizado junto ao curso deodontologia da Universidade Estadual de M ontes Claros - Unimontes. Nessa perspectiva, este artigo fundamenta a tese de "feminização" da odontologia através da literatura especializada no tema e concentra-se na revisão bibliográfica para analisar este fenômeno. Para ilustrar a feminização da profissão, utilizou-seum estudo de caso, queanalisou o número de pessoas, por sexo, inscritas no processo seletivo para o curso de graduação em odontologia da Unimontes, apresentando aquelas selecionadas e concluintes do referido curso.

\section{A mulher, o mercado de trabal ho ea odontologia}

Moysés ${ }^{5}$, através de dados coletados junto ao Consel ho Federal de O dontologia, em 2003, apresenta o perfil do cirurgião-dentista brasileiro. Segundo 0 autor, o comportamento da força de trabal ho das mulheres na odontologia, no Brasil, tem apresentado crescimento em intensidadeeem constância. 0 significativo aumento da atividade das mulheres é uma das mais importantes transformações ocorridas desde os anos de 1970, sendo que este fato resultou não somente da necessidade econômica e das oportunidades ofertadas pelo mercado, mas, também, foi devido às transformações demográficas, culturais e sociais que ocorrem no país e que afetaram as mulheres e as famílias do Brasil. 0 aumento da escolaridade e 0 acesso às universidades oportunizaram 0 acesso das mulheres a novos trabal hos ${ }^{1,3,4}$.

A expansão da escolaridade foi um fenômeno em maior intensidade no contingente populacional feminino. As mulheres conseguiram reverter um quadro de desigualdade e consolidar uma nova realidade, maior escolarização que os homens da população brasileira ${ }^{1,6}$.

A entrada feminina nas instituições deensino superior éum fenômeno recente; especificamente, referimo-nos ao boom ocorrido a partir da década de setenta, cujo impacto no campo do trabalho é, ainda, pouco dimensionado no estudo das profissões ${ }^{4,6}$. De 1991 a 2004, o número de estudantes do sexo feminino no ensino superior cresceu $181 \%$, sendo que o crescimento de estudantes masculinos foi de $148 \%$ ? 
A trajetória do aumento do contingente feminino com nível universitário éfundamental na medida em que 0 acesso às universidades reflete ascensão social e possi bilidade de melhores postos de trabalho. Além do crescimento da entrada feminina nas instituições de ensino superior, houve também um aumento nos índices de alfabetização das mulheres, que reverteram a tradicional desvantagem em relação aos homens ${ }^{1}$.

0 aumento dos índices de escolaridade das mulheres em todos os níveis educacionais, principalmente no nível superior, significa uma maior equidadedegênero. Essefato representa uma conquista, independentemente de a escolaridade ter resultado ou não em inserção laboral feminina ${ }^{1}$.

Sabe-se que o mercado de trabalho torna-se mais receptivo a quem está mais qualificado. Dessa forma, as mulheres mais instruídas apresentam maior participação no mercado, podendo ter atividades mais gratificantes e melhor remuneradas, compensando as despesas, com a estrutura doméstica, que suprem sua saída do lar ${ }^{1,3}$. Assim como acontece com os homens, a atividade das mulheres aumenta entre as quetêm mais de oito anos de estudo. Q uando as mesmas têm nível superior de ensino (quinze anos ou mais), elas tornam-se mais ativas ${ }^{3}$.

No entanto, o fato de as mulheres optarem em continuar os estudos por mais tempo pode estar relacionado à falta de alternativas no mercado de trabalho. 0 acesso crescente das mulheres a esses espaços representa avanço quando consideramos a educação como bem estruturador de novas relações de poder. Por outro lado, provavel mente, os homens abandonam o curso universitário pela necessidade de trabalhar, ou seja, a construção tradicional dele como o provedor da família. Deste modo, os cursos universitários, de um modo geral, vêm se feminizando como um todo'.

Torna-seimportante discutir nesteartigo não só o fato do aumento do índice de escolaridade das mulheres, mas também refletir sobre a segmentação sexual das profissões.

Conforme Silva ${ }^{4}$, pode-se observar uma hierarquia entre grupos profissionais, consequência das relações de poder vinculadas ao prestígio social de cada profissão. Essas relações de poder resultam da capacidade da profissão de gerar ganhos financeiros, de atender demandas, como também está associada à absorção de conhecimentos mais complexos.

Além das relações de poder entre as profissões, há uma tendência de segmentação sexual dos ramos de ensino, favorecida pelo próprio sis- tema escolar. Ou seja, as habilidades intrínsecas dos homens e mulheres seriam atributos construídos e reforçados a partir do início do processo de escolarização. Indícios de que a educação desempenha papel fundamental na naturalização dos papéis femininos e masculinos podem ser constatados através do rendimento escolar diferenciado, em que há concentração de mulheres em cursos secundários propedêuticos enquanto os homens concentram-se nos cursos profissionais. No imaginário coletivo dos espaços escolares, permeia a idéia de que mulheres teriam mais propensão às artes e à literatura (facilidade nas áreas articuladas à sensibilidade e emoção), enquanto os homens apresentariam aptidão nas ciências. Este fato acaba se tornando uma profecia autorrealizável e, sendo assim, os casos desviantes não recebem estímulos adequados ${ }^{1,4,8}$.

Dianteda segmentação sexual das profissões, a odontologia caracterizou-se como curso profissional masculino. Todavia, de acordo com Rabello et al. ${ }^{6}$, apoiadosna idéia, socialmenteaceita, da mulher como complemento do homem, sem expressão esem qual ificação, a odontologia sustentou-se como uma profissão masculina até as últimas duas décadas.

Assim, a participação feminina no mercado de trabalho tem sido afetada pela manutenção de um modelo familiar patriarcal, que se refere à hegemonia realizada pela figura masculina do pai ou marido, segundo o qual às mulheres cabem as responsabilidades domésticas e socializadoras. Portanto, esse modelo condiciona a participação feminina no mercado de trabal ho a fatores além daqueles referentes a sua qualificação eà oferta de emprego. Dessa forma, a necessidade de associar papéis familiares e profissionais limita a disponibilidade das mulheres para o trabalho $0^{1,3,6}$.

Rabello et al. ${ }^{6}$ afirmam que as primeiras muIheres ligadas à odontologia apareceram confirmando sua subalternidade aos homens, sendo auxiliares de seus maridos e assumindo a profissão após o seu falecimento.

Quando as mulheres ingressaram nas instituições de ensino superior, sobretudo a partir dos anos setenta, e na formação profissional, na mai oria das vezes, o ingresso dava-se em setores relacionados com suas aptidões ou qualidades naturais, sendo a segmentação sexual das profissões um dos mecanismos que permitiu a hierarquização profissional ${ }^{1,4}$.

No entanto, fatores como mudanças culturais e perda de prestígio do magistério primário afetaram diretamente a natureza do processo de escolarização superior feminino, levando a uma 
maior diversificação de carreiras. Porém, essa mudança relativa às ocupações caminha concomitantementecom a persistência dealgumas continuidades, apesar de diferentes áreas assistirem ao crescimento, ora maior ora menor, da participação de mulheres ${ }^{1,3}$.

Especificamente com relação às mudanças, 0 fato de a sociedade estabelecer novos códigos e práticas faz com que ocorra uma crescente opção das mulheres por carreiras universitárias com maior prestígio. Por sua vez, como condicionante resultado, a efetiva entrada feminina nos cursos universitários, historicamente considerados masculinos, influencia a construção de outros novos papéis sociais $s^{1,6}$.

Todavia, ainda que as mulheres estejam se inserindo em campos com mais prestígio - que estabelecem uma relação mais direta com o científico, como a medicina -, há uma tendência de elas ocuparem dentro de determinada área de conhecimento os lugares femininos - que são associados ao cuidar e ao materno, por exemplo, e que são hierarquicamente inferiores no campo profissional4,6. Essa associação é justificada pelo fato de que a mulher tende a ser reconhecida como um ser regido pela dimensão da natureza, do não político e da experiência e, em oposição, o homem como ser detentor da história, da ciência e da cultura.

Tais críticas sobre essa condição da mulher foram veementemente argumentadas por Beauvoir ${ }^{9}$ quando esta evidenciou que, na sociedade, existe uma tendência à naturalização da constituição do sexo. Segundo a autora, tal processo se fundamenta na justificativa proporcionada pelos dados da própria biologia. Essa ciência se pauta pela perspectiva mecanicista de garantir a hegemonia da condição biológica como determinante e constitutiva da natureza da mulher. Portanto, segundo tal perspectiva, a diferenciação entre os sexos se dá a partir das condições de reprodução, da perpetuação da espécie ou, ainda, na definiçãa da condição de ser macho ou fêmea. No seu entendimento, os homens e as mulheres são seres sociais e históricos. Seus corpos estão submetidos a valores, normas e leis.

A superação de tal naturalização nas carreiras relacionadas ao setor de saúde tem ocorrido, sobretudo, a partir dos anos setenta. Desde então, tem ocorrido um franco processo de feminização, apesar da tradicional vocação do setor em absorver mão de obra feminina para execução de grande parte das tarefas e funções no processo de trabalho ${ }^{10}$. É o caso, por exemplo, da enfermagem, quetradicionalmente absorvemulheres para suas atividades. M as, outras profissões passam por esse processo de feminização, profissões que historicamente eram masculinas, como medicina e odontologia. Essas profissões, ao longo de sua história, perdem a hegemonia masculina na sua composição e incorporam cada vez mais uma parcela considerável do contingentefeminino $0^{4,6,11}$.

$\mathrm{Na}$ odontologia, a inserção da mulher deu-se lentamente, acompanhando o desenvolvimento da sociedade, tanto histórico como cultural. A partir de 1970, observa-se o aumento gradual do interesse da mulher pela odontologia, concomitantemente a sua conscientização e transformação do seu papel diante da sociedade, na busca de status e melhoria da condição social ${ }^{6}$.

0 movimento feminista ocorrido na década de setenta se constituiu como uma manifestação de mulheres que, mesmo integrando diferentes classes sociais, viviam situações de discriminação muito semelhantes. Entre as conquistas daquelemovimento reivindicatório, as mulheresque possuíam melhores condições econômicas se inserem no ensino universitário e, consequentemente, entram no mercado de trabal ho ${ }^{1}$.

De certa forma, vários fatores influenciaram 0 aumento das mulheres no mercado de trabaIho, tais como o fato das mulheres diminuírem 0 número de filhos as liberou para o trabalho; a expansão da escolaridade aumentou as qualificações para enfrentar o mercado de trabalho; mudanças culturais como a valorização do exercício de uma atividade profissional incentivaram para o mundo do trabalho até mesmo quem teria outra opção. Outros fatores podem ser mencionados, como o empobrecimento a partir dos anos oitenta (devido a novas necessidades de consumo) e maiores gastos com a educação e a saúde dos filhos e dos familiares (as famílias da classemédia não podem mais prescindir do aporte econômico das mulheres) ${ }^{3}$.

Em termos percentuais, a inserção feminina no mercado de trabalho em 1970 representava 20,85\%; em 1980, 30\% e, em 1990, passou a $51,04 \%$. Contudo, as carreiras em que houve aumento da predominância feminina são as piores remuneradas no mercado de trabalho. Porém, apesar de ser forte a tendência de permanência das mulheres nestes segmentos menos remunerados, existe uma expansão da participação feminina em todas as carreiras ${ }^{1}$.

Nas ocupações técnicas, científicas, artísticas e assemelhadas, tem ocorrido o aumento do número demulheres em muitas ocupações e profissões de prestígio, entre as quais vale ressaltar a odontologia. O Censo Demográfico 1980: M ão 
de Obra e o de 1991 verificaram um aumento relativo de $170 \%$ do percentual feminino. Dados do mesmo censo confirmaram que a participação das mulheres aumentou consideravelmente também na medicina (137\%) e jornalismo (146\%). Outras profissões, como arquitetura, engenharia e advocacia, também apresentaram aumento da participação feminina. Ao lado dessas mudanças, ainda persistem al guns dos principais guetos femininos, como enfermagem, 0 magistério primário, a assistência social, dentre outras profissões. Observa-se também um aumento na participação das mulheres no ensino médio eno superior ${ }^{3,9}$. A verdade éque a participação da mulher na economia do país passou de cerca de 43,4\%, em 2004, para 43,7\%, em 2005, conforme a Pesquisa M ensal de Emprego, divulgada pelo Instituto Brasileiro de Geografia e Estatística (IBGE) ${ }^{7}$.

Da segregação ao gueto, homens e mulheres convivem no mesmo espaço profissional, à mixidade degênero, o quepressupõe condiçõesigualitárias de exercício das funções. 0 fato de as mulheres estarem se inserindo dentro de setores anteriormente masculinos, com exigência de alta qualificação, abre novas perspectivas, visando ao sentido de promoção de igualdades num primeiro momento. A partir daí, passou-se a argumentar no sentido de suprimir as diferenças entre gêneros no mercado de trabalho ${ }^{4}$.

Feminização do curso de odontologia da Universidade Estadual de M ontes Claros - Unimontes

O curso de graduação em odontologia da Unimontes foi implantado em 1997 e, até 0 ano de 2006, graduaram-se dez turmas. Para o estudo de caso, analisou-se o número de pessoas, por sexo, inscritas e concluintes do referido curso, no período de 1997 a 2006. Todavia, no que diz respeito ao processo seletivo, estaremos apenas analisando o período de 1999 a 2006, devido à falta dos dados correspondentes aos anos de 1997 e 1998. Os dados secundários foram obtidos juntamente à Comissão Técnica de Concurso (COTEC) da Universidade Estadual de Montes Claros - Unimontes ena Secretaria Geral da mesma instituição.

Os dados foram divididos em dois grupos de análise. Um que corresponde ao número de homens e mulheres inscritos no processo seletivo para o ingresso no curso de odontologia e o segundo grupo agrega tanto as análises dos ho- mens e mulheres que foram aprovados como aqueles e aquelas que integralizaram o curso de graduação em análise. Dado ao exposto, a questão priorizada para a análise desenvolvida neste trabalho centra-se nas diferenças, por sexo, presentes nesses processos. Os dados foram submetidos à análise estatística descritiva através de frequência absoluta e relativa.

Em todos os processos seletivos da Unimontes, entre o período compreendido do segundo semestre de 1999 ao segundo semestre de 2006, há uma superação do contingente feminino no número de inscrição para o curso de odontologia, sendo que o número de mulheres que participaram do vestibular (4.276) para o referido curso é bem maior que o número de homens, perfazendo um total equivalente a $65,16 \%$ do total de indivíduos inscritos. Tais constatações são advindas da Tabela 1, que apresentamos em seguida.

0 Gráfico 1 ilustra bem essa diferença entre homens emulheres no processo seletivo, em que a procura pelo curso de odontologia na Universidade Estadual de M ontes Claros, Unimontes, é majoritariamente das mulheres.

Tabela 1. Distribuição do contingente de inscritos por sexo no processo seletivo para o curso de odontologia da Universidade Estadual de M ontes Claros, Unimontes, Brasil, no período de 1999 a 2006, por semestre.

\begin{tabular}{|c|c|c|c|c|}
\hline \multirow[t]{2}{*}{ Semestre/Ano } & \multicolumn{2}{|c|}{ Masculino } & \multicolumn{2}{|c|}{ Feminino } \\
\hline & $\mathrm{n}$ & $\%$ & $\mathrm{n}$ & $\%$ \\
\hline $2 / 1999$ & 360 & $41,38 \%$ & 510 & $58,62 \%$ \\
\hline $1 / 2000$ & 181 & $37,09 \%$ & 307 & $62,91 \%$ \\
\hline $2 / 2000$ & 221 & $32,55 \%$ & 398 & $67,45 \%$ \\
\hline $1 / 2001$ & 132 & $30,99 \%$ & 294 & $69,01 \%$ \\
\hline $2 / 2001$ & 160 & $34,00 \%$ & 309 & $66,00 \%$ \\
\hline $1 / 2002$ & 159 & $34,41 \%$ & 303 & $65,59 \%$ \\
\hline $2 / 2002$ & 134 & $32,76 \%$ & 275 & $67,24 \%$ \\
\hline $1 / 2003$ & 107 & $30,06 \%$ & 249 & $69,94 \%$ \\
\hline $2 / 2003$ & 122 & $31,61 \%$ & 264 & $68,39 \%$ \\
\hline $1 / 2004$ & 150 & $35,38 \%$ & 274 & $64,62 \%$ \\
\hline $2 / 2004$ & 120 & $32,70 \%$ & 247 & $67,30 \%$ \\
\hline $1 / 2005$ & 101 & $30,15 \%$ & 234 & $69,85 \%$ \\
\hline 2/2005 & 129 & $33,95 \%$ & 251 & $66,05 \%$ \\
\hline $1 / 2006$ & 94 & $34,18 \%$ & 181 & $65,82 \%$ \\
\hline $2 / 2006$ & 115 & $39,25 \%$ & 178 & $60,75 \%$ \\
\hline Total & 2.285 & $34,84 \%$ & 4.274 & $65,16 \%$ \\
\hline
\end{tabular}

Fonte: Comissão Técnica de Concurso (COTEC), Universidade Estadual de M ontes Claros, U nimontes, Brasil, 2006. 
No que diz respeito ao número de ingressose

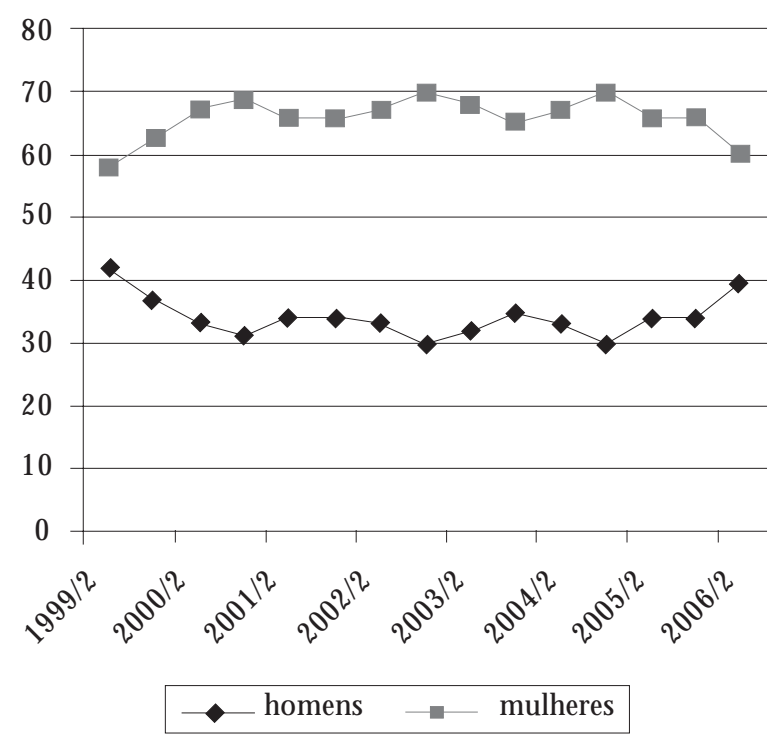
formados, observa-se na Tabela 2 que da porcentagem total de pessoas que ingressaram no curso de odontologia da Unimontes, o contingente feminino foi superior, perfazendo um total de 227 mulheres ou $52,43 \%$ do total.

Para os que concluíram o curso, no período referente ao primeiro semestre de 2002 ao segundo semestre de 2006, nota-se que a maioria dos formados $(61,40 \%)$ é do sexo feminino. Analisando as dez turmas concluintes do curso, separadamente, observa-se queo número superior de formados do sexo feminino refere-se, praticamente, à maioria das turmas, com exceção para as que formaram no segundo semestre de 2004 eno primeiro semestre de 2006. É interessante observar que, em $30 \%$ de todas as turmas formadas, a superioridade da porcentagem de mulheres sobre os homens émuito expressiva, ficando na faixa de $80 \%$ do total de concluintes na turma.

Gráfico 1. Distribuição da frequência relativa, por semestre, do contingente de inscritos, por sexo, no processo seletivo para o curso de odontologia da Universidade Estadual de Montes Claros, Unimontes, Brasil, no período do 20 semestre de 1999 ao 2o semestre de 2006.

Tabela 2. Distribuição do contingente de ingressos e formados por sexo no curso de odontologia da Universidade Estadual de M ontes Claros, Unimontes, Brasil, no período de 1997 a 2006, por semestre.

\begin{tabular}{|c|c|c|c|c|c|c|c|c|}
\hline \multirow{4}{*}{ Semestre/Ano } & \multicolumn{8}{|c|}{ Sexo } \\
\hline & \multicolumn{4}{|c|}{ Masculino } & \multicolumn{4}{|c|}{ Feminino } \\
\hline & \multicolumn{2}{|c|}{ Ingressos } & \multicolumn{2}{|c|}{ Formados } & \multicolumn{2}{|c|}{ Ingressos } & \multicolumn{2}{|c|}{ Formados } \\
\hline & $\mathrm{n}$ & $\%$ & $\mathrm{n}$ & $\%$ & $\mathrm{n}$ & $\%$ & $\mathrm{n}$ & $\%$ \\
\hline 2/ 1997 & 09 & $45,00 \%$ & - & - & 11 & $55,00 \%$ & - & - \\
\hline 1/ 1998 & 07 & $33,33 \%$ & - & - & 14 & $66,67 \%$ & - & - \\
\hline 2/ 1998 & 12 & $60,00 \%$ & - & - & 08 & $40,00 \%$ & - & - \\
\hline 1/ 1999 & 10 & $47,62 \%$ & - & - & 11 & $52,38 \%$ & - & - \\
\hline 2/ 1999 & 10 & $50,00 \%$ & - & - & 10 & $50,00 \%$ & - & - \\
\hline $1 / 2000$ & 15 & $75,00 \%$ & - & - & 05 & $25,00 \%$ & - & - \\
\hline 2/ 2000 & 06 & $30,00 \%$ & - & - & 14 & $70,00 \%$ & - & - \\
\hline 1/ 2001 & 09 & $45,00 \%$ & - & - & 11 & $55,00 \%$ & - & - \\
\hline 2/ 2001 & 12 & $60,00 \%$ & - & - & 08 & $40,00 \%$ & - & - \\
\hline 1/ 2002 & 07 & $35,00 \%$ & 04 & $33,33 \%$ & 13 & $65,00 \%$ & 08 & $66,67 \%$ \\
\hline 2/ 2002 & 09 & $45,00 \%$ & 09 & $37,50 \%$ & 11 & $55,00 \%$ & 15 & $62,50 \%$ \\
\hline 1/ 2003 & 12 & $60,00 \%$ & 08 & $50,00 \%$ & 08 & $40,00 \%$ & 08 & $50,00 \%$ \\
\hline 2/ 2003 & 05 & $25,00 \%$ & 11 & $47,82 \%$ & 15 & $75,00 \%$ & 12 & $52,18 \%$ \\
\hline 1/ 2004 & 13 & $46,43 \%$ & 04 & $20,00 \%$ & 15 & $56,57 \%$ & 14 & $80,00 \%$ \\
\hline 2/ 2004 & 07 & $28,00 \%$ & 14 & $58,33 \%$ & 18 & $72,00 \%$ & 10 & $41,67 \%$ \\
\hline 1/ 2005 & 16 & $61,54 \%$ & 04 & $20,00 \%$ & 10 & $38,46 \%$ & 14 & $80,00 \%$ \\
\hline $2 / 2005$ & 14 & $53,85 \%$ & 10 & $33,33 \%$ & 12 & $46,15 \%$ & 20 & $66,67 \%$ \\
\hline 1/ 2006 & 18 & $45,00 \%$ & 15 & $57,70 \%$ & 22 & $55,00 \%$ & 11 & $32,30 \%$ \\
\hline $2 / 2006$ & 13 & $54,17 \%$ & 04 & $16,67 \%$ & 11 & $45,83 \%$ & 20 & $83,33 \%$ \\
\hline Total & 206 & $47,57 \%$ & 83 & $38,60 \%$ & 227 & $52,43 \%$ & 132 & $61,40 \%$ \\
\hline
\end{tabular}

Fonte: Comissão Técnica de Concurso (COTEC) e Secretaria Geral da U niversidade Estadual de M ontes Claros, U nimontes, Brasil, 2006. 
Analisando a diferença entre os sexos, no que diz respeito tanto ao ingresso como também à conclusão do curso de odontologia da Unimontes, foi encontrada uma porcentagem do contingente de mulheres em ambas as situações analisadas, diferença presente desdea implantação do curso (Gráficos 2 e 3).

Conforme Brustolin et al. ${ }^{12}$, a Faculdade de Odontologia da Universidade do Planalto Catarinense (UNIPLAC) apresenta um predomínio de acadêmicos do sexo feminino $(53,3 \%)$. Os autores afirmam que o fato foi verificado em outros estudos, que confirmaram a tendência crescente de feminização das profissões no setor da saúde, e citam os seguintes autores: Arbenz et al. ${ }^{13}$, Botti e Santos ${ }^{14}$, Freire et al. ${ }^{15}$, Freitas e Nakayama ${ }^{16}$, Carvalho et al. ${ }^{17}$, Costa et al. ${ }^{18} \mathrm{e}$ Junqueira et al. ${ }^{19}$.

0 estudo de Guedes ${ }^{1}$ analisa os Censos De mográficos de 1970 e 2000 do Instituto Brasileiro de Geografia e Estatística (IBGE) e conclui queo número de formados mulheres em odontologia foi $18 \%$ ehomens, $82 \%$ em 1970 , e de $51 \%$ e $49 \%$ respectivamente, em 2000 , demonstrando a feminização da profissão.

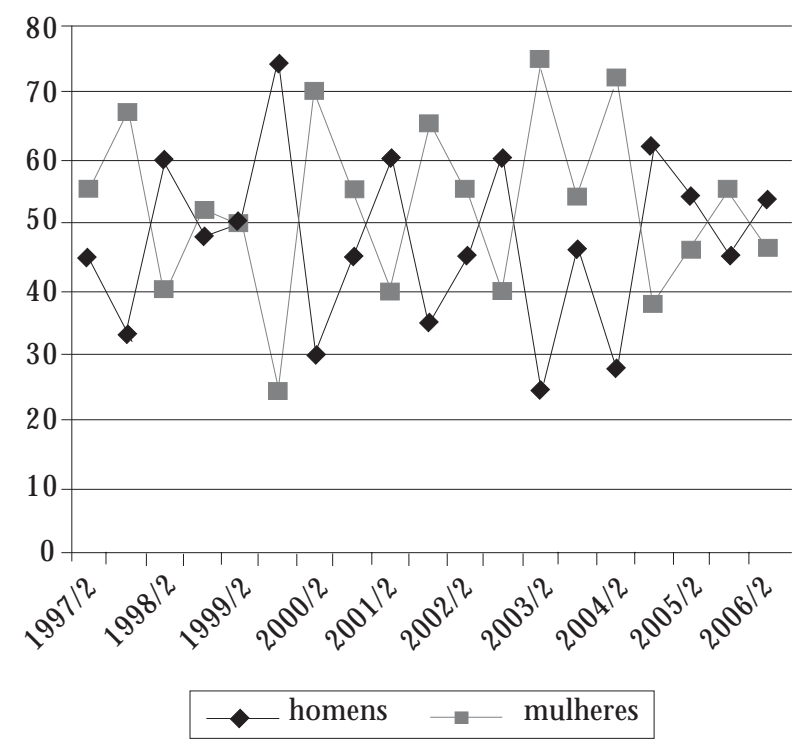

Gráfico 2. Distribuição da frequência relativa, por semestre, do contingente de ingressos, por sexo, no curso de odontologia da Universidade Estadual de M ontes Claros, Unimontes, Brasil, no período do $2^{\circ}$ semestre de 1997 ao $2^{\circ}$ semestre de 2006.
Para M oimaz ${ }^{20}$, o processo de feminização da força de trabal ho na odontologia tem sido relatado por vários autores e o incremento no número de mulheres na odontologia é um dado também observado nos Estados Unidos e Europa.

Bruschini ${ }^{3}$ analisa dados do Censo Demográfico 1980: M ão de Obra eo de 1991, no Brasil, e afirma que na odontologia, em 1980, o grupo feminino correspondia a $28,6 \%$ dos cirurgiõesdentistas, sendo que, em 1991, este número subiu para $42,4 \%$ do total de profissionais no Brasil. Também Guedes ${ }^{1}$ analisou o Censo Demográfico de 1970 e 2000 do Instituto Brasileiro de Geografia eEstatística (IBGE) eafirma quea proporção de formados por sexo na odontologia em 1970 era de $18 \%$ de mulheres para $82 \%$ de homens, enquanto, em 2000, esta relação passou para $51 \%$ demulheres para $49 \%$ dehomens. Ainda com relação ao censo de 2000 , Beltrão e Teixeira ${ }^{10}$ afirmam que $46 \%$ das carrei ras possuem proporção maior de mulheres, sendo a odontologia uma delas.

A feminização da odontologia nos faz refletir sobre a afirmação de Silva ${ }^{4}$, que diz que a proletarização dos profissionais refletena sobrevivên-

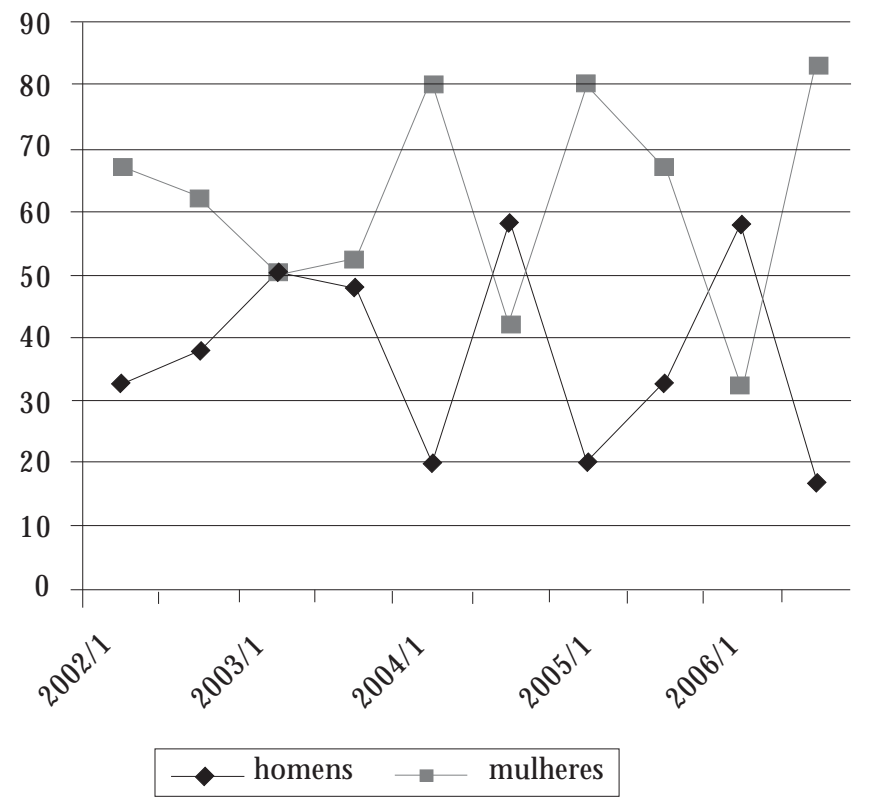

Gráfico 3. Distribuição da frequência relativa, por semestre, do contingente de formados, por sexo, no curso de odontologia da U niversidade Estadual de M ontes Claros, Unimontes, Brasil, no período do $1^{\circ}$ semestre de 2002 ao 2ํㅡ semestre de 2006. 
cia do modelo profissional liberal, cujo alicerceé a autonomia, e que está em crise. No estudo de M oimaz ${ }^{20}$, as cirurgiãs-dentistas entrevistadas relataram insatisfação com a profissão, sendo que $9,1 \%$ afirmaram que um dos motivos seria a desvalorização do profissional da odontologia.

É interessante refletir sobre a coincidência temporal entre 0 aumento da absorção de muIheres e as mudanças na organização do mercado. 0 que pode ter sido um fato coincidentetorna-se, em alguns momentos, uma explicação, isto é, o setor se desqualificou porque se feminilizou ou se feminilizou porque se desqualificou 4 .

Ainda na mesma linha de pensamento, há uma discussão embasada nas pesquisas que abordam a ausência da mixité nos espaços profissionais quetradicionalmenteeram masculinos e que foram conquistados pelo grupo feminino. Esses espaços apresentam problemas de dimensões interessantes quanto à segmentação do mercado de trabalho por sexo. Sendo que as mulheres não conquistaram, por seus próprios méritos, a inserção nesse universo masculino, elas foram aceitas e, desta forma, têm que corresponder às exigências com mais rigor, a qualquer custo. Existe uma associação entre a inserção de mulheres em alguns setores e a desvalorização desses setores no mercado de trabalho ${ }^{4}$.

Dessa forma, M oimaz ${ }^{20}$, com base em pesquisa, afirma que o aumento demulheresna profissão traz conquistas, já que $68 \%$ das cirurgiãsdentistas entrevistadas relataram não encontrar dificuldades no exercício da profissão e $78 \%$ afirmaram satisfação com a odontologia.

Estefato demonstra que as mulheres, de certa forma, estão crescendo, não só em números, como também há um crescimento qualitativo no quediz respeito à inserção na odontologia. Daí a importância desse estudo, pois a constatação quantitativa da feminização do curso de odontologia da Unimontes nos leva a novas perspectivas de investigações, no sentido de compreender seessecrescimento numérico também reflete em crescimento qualitativo.

\section{Considerações finais}

No Brasil, os dados revelam que as mulheres constituem a maior parte dos estudantes denível superior do país. A inserção das mulheres nas instituições de ensino superior, na década de setenta, representa um marco das mudanças na sociedade, já que a mesma considerava a universidade um espaço masculino.
Dianteda segmentação sexual das profissões, a odontologia caracterizou-se como profissão masculina até as últimas duas décadas. A efetiva entrada feminina nos cursos universitários, historicamente considerados masculinos, influencia a construção de outros novos papéis sociaise abre novas perspectivas de promoção de igualdades. No entanto, existe uma associação entre a inserção feminina em al guns setores e a desvalorização desses setores no mercado de trabalho.

No entanto, apesar do avanço da inserção das mulheres no ensino superior, sob o ponto de vista quantitativo, Guedes ${ }^{1}$ alerta que al guns aspectos de exclusão esegmentação do processo de entrada das mulheres nas universidades são mascarados. Queremos dizer com tal adjetivo que a igualdade numérica nem sempre condiz com uma equidade de gênero, uma vez que as mulheres continuam concentradas nas áreas de menor prestígio e menos remuneradas, apesar desse processo modificar-selentamente. Essa argumentação é corroborada por Silva ${ }^{4}$, quando afirma que a entrada feminina nos campos masculinos é interpretada, por alguns autores, com base no discurso igualitário, o qual nega as diferenças de gênero, que desapareceriam no interior do campo profissional. Entretanto, há argumentos na perspectiva do surgimento de novas fronteiras que envolvem a divisão sexual do trabalho. Apesar de todas estas questões colocadas, a inserção das mulheres na odontologia caracteriza um avanço, pois apesar de ter sido lento, o mesmo acompanhou o desenvolvimento histórico e cultural da sociedade.

0 acesso às universidades é fruto do processo de modernização e de mudança cultural no nosso país e oportunizou a inserção das mulheres em novos postos de trabalhos, mais gratificantes e melhor remunerados, considerando a educação como bem estruturador denovas relações de poder.

O curso de graduação em odontologia da Universidade Estadual de Montes Claros, Unimontes, desde a sua implantação, tem apresentado uma maior porcentagem de mulheres, tanto com relação aosingressos $(52,43 \%)$ como também em relação aos formados (61,40\%). A diferença entre homens e mulheres já se inicia desde o processo seletivo, em que a procura pelo curso é majoritariamente das mulheres $(65,16 \%)$.

0 referencial teórico analisado vai ao encontro dos dados empíricos desse estudo de caso, donde se conclui que o fenômeno da feminização também ocorre no curso de odontologia da Unimontes. 


\section{Colaboradores}

SM Costa, SJ A Durães e M H N G de Abreu trabaIharam na concepção da pesquisa, coleta dos dados, tabulação, análise e interpretação dos dados, redação do artigo final.

\section{Referências}

1. Guedes MC. O contingente feminino de nível universitário nos últimos trinta anos do século $X X$ : a reversão de um quadro desigual In: XIV Encontro Nacional de Estudo Populacional, ABEP; 2004; Caxambu, M G. [acessado 2006 set]. Disponível em: http://www.abep.nepo.unicamp.br/site_eventos_ abep

2. Schwartzman S. A diferenciação do ensino superior no Brasil. In: Segunda reunião do "Projeto Regional de Estudos sobre Políticas de Educação Superior"; 1999; Buenos Aires. [acessado 2006 set]. Disponível em: http://www.schwartzman.org.br

3. Bruschini $C$. Trabalho feminino no Brasil: novas conquistas ou persistência da discriminação? (Brasil,1985-1995). In: Rocha M IB, organizador. TrabaIho e gênero: mudanças, permanências e desafios. São Paulo: Editora 34; 2000. p. 13-58.

4. Silva DPM. 0 intercurso das Imagens profissionais do M édico e do Assistente Social sob a ótica do Gênero. In: Seminários DIM AC, IPEA, no 127. Grupo de Trabalho 4. [acessado 2006 jun 06]. Disponível em: http://www.desafio.ufba.br

5. Moysés SJ. Políticas de saúde e formação de recursos humanos em Odontologia. Rev. ABENO 2004; 4 (1):30-37.

6. Rabello SB, Godoy CVC, Padilha WW N. Por que a Odontologia se transformou numa profissão de mulheres? Rev Bras Odontol [periódico na Internet] 2000 [acessado 2006 jun 06]; 57(2):[cerca de 9 p.]. Disponível em: http://www. odontologia.com.br/ artigos.asp

7. Viva a mulher brasileira. Jornal do Conselho Federal de Odontologia 2006; 70:13.

8. Stewart FM, Drumond Jr. Women and the world of dentistry. Br Dent. J. 2000; 1888 (1):7-8.

9. Beauvoir S. 0 segundo sexo. 8a ed. Rio de Janeiro: Nova Fronteira; 1991.

10. Beltrão KI, Teixeira M P. 0 vermelho e o negro: raça e gênero na universidade brasileira - uma análise da seletividade das carreiras a partir dos censos demográficos de 1960 a 2000 [Texto para discussão]. Brasília: IPEA; 2004.
11. Labra ME. Mulher, Saúde e Sociedade no Brasil. Petrópolis: Vozes; 1989.

12. Brustolin J, Brustolin J, Toassi RFC. Perfil do acadêmico de Odontologia da Universidade do Planalto Catarinense - Lages - SC, Brasil. Rev. ABENO 2006; 6(1):70-76.

13. Arbenz GO, Abramowicz M, Abramowicz M, Silva $M$. Motivos conscientes na escolha da profissão odontológica. Rev Fac O dontol U niv São Paulo 1973; 1(11):101-109.

14. Botti MRV, Santos GM C. Perspectiva do exercício profissional na odontologia. RGO 1986; 2(34):155159.

15. Freire MCM, Souza CS, Pereira HR. O perfil do acadêmico de Odontologia da Universidade federal de Goiás. Divulgação em Saúde para D ebate 1995; 10:15-20

16. Freitas SFT, Nakayama MH. Um perfil do estudante de Odontologia no estado de São Paulo. Divulgação em Saúde para Debate 1995; 10:29-37.

17. Carvalho DR, Perri de Carvalho AG, Sampaio H. M otivações e expectativas para o curso e para 0 exercício da Odontologia. Rev Assoc Paul Cir Dent 1997;51(4):345-349.

18. Costa ICC, Marcelino G, Saliba NA. Perspectivas de um grupo de alunos de odontologia sobre a profissão no terceiro milênio. Rev ABOPREV 1999; 2(1):38-45.

19. Junqueira JC, Colombo CED, Tavares PG, Rocha $R F$, Carvalho YR, Rodrigues JR. Quem é e o que pensa o graduando de odontologia. Rev Odontol UNESP. 2002; 31(2):269-284.

20. Moimaz SAS, Saliba NA, Blanco MRB. A Força do Trabalho Feminino na Odontologia, em Araçatuba - SP. J Appl Oral Sci. 2003; 11(4):301-305.

Artigo apresentado 18/03/2007

Aprovado em 14/01/2008 